\title{
Injuries in whitewater kayaking
}

\author{
D C Fiore, J D Houston
}

\begin{abstract}
Objective-To provide epidemiological data on whitewater kayaking injuries using a descriptive study.

Methods-A retrospective survey was distributed at whitewater events and club meetings, and made available and advertised on the world wide web, through postings and announcements to newsgroups, related sites, and search engines. Data on sex, age, experience, and ability were collected. Injury data collected included mechanism, activity, difficulty of rapid, and self reported severity.

Results-Of the 392 kayaking respondents included in the final analysis, 219 suffered 282 distinct injury events. The number of days spent kayaking per season was the only independent predictor of injury. The overwhelming majority of injuries occurred while the kayaker was still in the boat $(87 \%)$. Striking an object was the most common mechanism of injury (44\%), followed by traumatic stress and overuse $(25 \%$ each). The most common types of injury were abrasion ( $25 \%)$, tendinitis $(25 \%)$, contusion (22\%), and dislocation (17\%). The upper extremity, especially the shoulder, was the most commonly injured area of the body. Although half of injured kayakers sought medical care for their injury, and almost one third missed more than one month of kayaking because of the injury, almost all $(96 \%)$ reported a complete or good recovery.

Conclusions-Factors relating to likelihood of injury appear to be connected with exposure, namely the number of days a year that the sport was pursued. Except
\end{abstract}

Accepted 3 May 2001

Table 1 International scale of river difficulty

\begin{tabular}{ll}
\hline River class & Explanation \\
\hline Class I & Easy: waves small; passages clear; no serious obstacles. \\
Class II & $\begin{array}{l}\text { Medium: rapids of moderate difficulty with passages clear. Most open } \\
\text { canoeists should never tackle anything tougher than class II. }\end{array}$ \\
Class III & $\begin{array}{l}\text { Difficult: rapids are longer and rougher than class II. Waves numerous, } \\
\text { high, irregular; rocks; eddies; rapids with passages clear though narrow, } \\
\text { requiring expertise in manoeuvring; scouting usually needed. Requires } \\
\text { good operator and boating equipment. }\end{array}$
\end{tabular}

Class IV Very difficult: rapids are generally longer, steeper and more heavily obstructed than class III rapids. Waves powerful, irregular; dangerous rocks; boiling eddies; passages difficult to scout; scouting mandatory first time; powerful and precise manoeuvring required. Demands expert boatman and excellent boat and outfit.

Class V Extremely difficult: exceedingly difficult, long and violent rapids, following each other almost without interruption; riverbed extremely obstructed; big drops; violent current; very steep gradient; close study essential, but often difficult. Requires best man, boat, and outfit suited to the situation. All possible precautions must be taken.

Class VI Extreme and expedition: rapids which have rarely been run. Once such a rapid has been repeatedly run, it is usually reclassified as a class 5x. Risk to swimmers and boaters is extremely high. for class $V$ (extreme) kayakers, reports of injuries paralleled the number of participants. Kayakers reported injuries predominantly on rivers that they assessed to be at a level appropriate to their skills. (Br f Sports Med 2001;35:235-241)

Keywords: kayaking; whitewater; injuries

Whitewater kayaking is fast becoming one of the most popular of the new "adventure sports", with images of kayaking used in advertising for everything from soft drinks to automobiles. Current estimates place the number of whitewater kayakers at between 1.4 and 2.8 million, with a growth of almost $15 \%$ annually. ${ }^{1-3}$ Although kayaking is often considered a very dangerous sport, little is actually known about the risks and types of injury. In 1981, Kizer ${ }^{4}$ performed a survey of 1000 whitewater kayakers, with 211 responses, concerning medical problems associated with kayaking. He found that $80 \%$ of kayakers were male, with almost one half $(46 \%)$ kayaking at least once a week (on average). The most common medical complaints, other than blisters (reported by $65 \%$ ), were muscle strain $(45 \%)$, low back strain $(31 \%)$, sprains or tendinitis $(28 \%)$, and submersion trauma $(17 \%)$. Other articles published in the medical literature that discuss injuries and hazards related to whitewater boating have been either case studies ${ }^{5-7}$ or review articles covering multiple whitewater related risks..$^{8-10}$ In addition, case reports, particularly of fatalities, have been collected and published by Charles Walbridge. ${ }^{11-14}$

As the popularity of whitewater kayaking continues to increase, doctors may expect to see more patients who are injured while participating in this activity. The unique demands of the sport, navigating down river and/or playing in whitewater hydraulics (holes and waves) in a small plastic boat, places the kayaker in a position where the line between excitement and injury may be very fine. Kayakers sit in their hard plastic boats with a "sprayskirt" around their waist which keeps water out of the boat. A quick pull on a drawcord allows a "wet exit" from the boat if the kayaker is knocked upside down and is unable to (Eskimo) roll back up. The kayaker uses a double bladed paddle for steering and propulsion. With the correct technique, the torso and lower extremity are used for much of the force applied to the paddle. If the technique is not correct, however, a sudden unexpected force against the paddle can often result in stress in the upper extremity, particularly the shoulders. Kayakers rate river difficulty on a scale of class I to class VI, and they rate themselves on the basis of the most difficult level of river that they are comfortable kayaking (table 1). 


\section{University of Nevada \\ School of Medicine \\ The Paddling Injury Study}

\begin{abstract}
$\underline{\text { Introduction }}$
\end{abstract}
Dear Paddler,

Paddling is an adventurous, exciting sport that is quickly growing in popularity. With the increasing number of participants comes the possibility of increased injuries. We are studying the types of injuries that occur while paddling on rivers, lakes, or the ocean. We are interested in your experiences in paddling, and the injuries that may have occurred in this sport. By taking a couple of minutes to fill out the survey, whether or not you have been injured while paddling, you will be part of an ongoing research project in which the goal is to document these injuries (or lack of), and to contribute to the prevention of injuries in the future.

The Paddling Injury Study is supported by The Univerity of Nevada School of

Medicine. The most important element of this research is your input. Please take a few minutes to tell us about your paddling experience and any paddling-related injuries you may have suffered over the past five years. If you have not been injured, please answer the questions that pertain to you. If you have been injured, please fill out one injury event per form and use as many forms as you need.

It is not necessary to put your name on the form, as data will remain anonymous. Each survey will include a Survey Identification Number to tag questionnaires. If you have more than one injury form, will you please transfer your number to the additional sheets.

If you have already completed this survey in either a printed or electronic form, please do not submit a second survey.

If you have questions or would like to make comments please write to: David C. Fiore, MD

Dept. of Family and Community Medicine

Univ. of Nevada School of Medicine

Reno, NV 89557

Thank you for your time and input; your paddling history is a valuable resource, and your assistance is greatly appreciated.

David C. Fiore, MD

Jeffery D. Houston, MS4

Shana M. Beaver

Figure 1 Survey form (continued).

This study was designed to acquire primarily epidemiological data on these injuries. The following were studied: the basic characteristics of injured and non-injured kayakers, mechanisms of injury, type of injury, severity of injury, and conditions leading to injury. By identifying the factors involved in injury, it may be possible to modify risks and reduce injuries.

\section{Methods}

SUBJECTS

The subjects were whitewater boaters who responded to either face to face or internet surveys. The former were limited geographically to the west coast (whitewater clubs in Reno, Nevada; Seattle, Washington; Redding and Chico, California; and whitewater events in Reno and Coloma, California). Internet respondents were not limited geographically or by participation in events.

\section{INSTRUMENTS/PROCEDURES}

Data on injuries caused by whitewater kayaking within the previous five years were collected in 1997 and 1998, using face to face interviews or the same survey placed on the internet (fig 1). For face to face interviews, participants were interviewed at river access points, during river races, and during whitewater club events. No data were collected from whitewater boaters who declined to participate, and no count was kept of these boaters. Notification of the web site was made through a link to the American
Whitewater homepage, postings in a whitewater newsgroup, and listing with several search engines. A brief explanatory paragraph was linked to the website containing the survey. The web based survey was designed so that incomplete or incorrectly completed surveys could not be submitted. Data were collected from May 1997 to September 1997. The study analyses results from whitewater kayakers only. Data collected included basic details, skill level, and information on specific injury events. Respondents may have had more than one injury event, and each event could include multiple injury types (abrasion, tendinitis, sprain, fracture), and may have involved more than one body part. Time off from kayaking because of injury was used as a marker of injury severity. Recovery was rated as poor, good, or complete, with explanations for less than complete recovery.

STATISTICAL ANALYSIS

SPSS version 10 (SPSS Inc, Chicago, Illinois, USA) was used for all statistical analysis. Logistic regression was used to study factors related to the likelihood of injury.

\section{Results}

RESPONDENTS

Data were collected on 579 whitewater participants: 110 were interviewed face to face and 469 via the internet. Of these, 29 were excluded from the internet data for being multiple entries, and 26 were excluded from the hand collected data for being incomplete. Of the remaining 524 respondents, 392 were whitewater kayakers.

\section{DESCRIPTIVE FEATURES}

Of the 392 kayakers, most of the respondents were male $(83 \%)$ with a mean age of 34 years (range 13-70) and an average number of years boating of $7.7(0-55)$. Some $77 \%$ of the respondents spent more than 20 days a year kayaking. A total of 219 injured kayakers (56\% of respondents) reported 282 injury events, causing 396 distinct anatomical injuries (table 2 ). Figure 2 shows the distribution of injured $v$ non-injured kayakers separated by class of boater at the time of the survey. Extreme kayakers (class V/VI) suffered injuries significantly more often $(76 \%)$ than the other classes of kayakers combined (50\%).

Most injuries occurred while the kayaker was in the river, with $87 \%$ occurring while in the boat and another $8 \%$ while "swimming"-that is, the kayaker was forced to abandon the kayak and was still in the river at the time of injury. Only 5\% occurred while the kayaker was walking or portaging (carrying the kayak to or from the river, or around a difficult rapid). The most common mechanism of injury was striking an object in the river (40\%), followed by traumatic stress injuries (the impact of water against the body or equipment, as in a dislocated shoulder from an overextended brace) and overuse injuries, both reported by a quarter of the injured kayakers (fig 3).

The most common types of injury were abrasion (25\%), tendinitis (25\%), contusion 


\section{University of Nevada School of Medicine}

The Paddling Injury Study

Part I: Demographics

1. What type of craft do you usually boat?

$\begin{array}{ll}\bigcirc \text { River Kayak } & \bigcirc \text { Raft } \\ \bigcirc \text { Closed Canoe } & \bigcirc \text { Open Canoe }\end{array}$

2. Please indicate the average number of days in which you paddle in one year.

$\begin{array}{lll}0-5 \text { days } & 11-20 \text { days } & 50+\text { days } \\ 6-10 \text { days } & 21-50 \text { days } & \end{array}$

3. What is the highest class river you feel comfortable leading (assuming you do know the river)?
$\bigcirc \mathrm{I}$
$\bigcirc$ III
$\mathrm{V}$
$\bigcirc$ II
O IV
VI

4. Please indicate:

Your age:

Years paddling:

(rounded to the nearest whole year)

Gender:

Male $\bigcirc$ Female

5. Have you had an injury (acute or chronic) due to boating in the past $\mathbf{5}$ years?

Yes (Please continue to Part II)

No (Since you have not been injured while paddling during the last 5 years, you have now finished the survey! Thank you for participating in the Paddling Injury Study.)

Figure 1 continued.

(22\%), and dislocation (17\%) (fig 3). Some 242 injuries were to the upper extremity (61\% of reported injuries), with almost half of these injuries involving the shoulder, of which 56 were dislocations.

Few injuries had long term sequelae; although $51 \%$ of the injured kayakers sought medical care for their injuries, $96 \%$ reported good or complete recovery. However, of those injured in the year before completing the survey, $8.7 \%$ reported poor recovery. Almost $30 \%$ of injured kayakers did not take any time off from the sport, but another $30 \%$ reported missing more than one month of kayaking. Of those with injuries caused by traumatic stress, $51 \%$ missed over one month of kayaking because of injury, whereas $31 \%$ of those with overuse injuries and only $18 \%$ of those with impact injuries missed over one month of kayaking.

Results of logistic regression analysis evaluating sex, age, number of days of participation per season, number of years kayaking, and skill level (class I/II, beginner/novice; class III/IV, intermediate; class V/VI, expert) showed that only the number of days spent kayaking per season and skill level of the kayaker were significantly related to the likelihood of injury. Expert and novice kayakers were injured more often than intermediate kayakers, although, because of their numbers, most injuries occurred to intermediate kayakers. The type of injuries suffered by kayakers also differed depending on their skill level. Beginner and novice kayakers had more impact injuries than 


\section{Part II: Injury Characterization}

Please use one survey form for each injury event.

1. During what activity did your injury take place?

(Please select only one option.)

river kayaking

river canoeing (open or closed)

river rafting (including inflatable kayaks)

other (please specify below)

2. How did this injury take place? (Please select only one option.)

impact injury (eg hitting a solid object)

traumatic stress (eg force of water against body, shoulder dislocation)

chronic overuse (eg tendinitis)

other

3. Did this injury occur while you were in your boat, while swimming, or while walking/portaging?

$\bigcirc$ boat $\bigcirc$ walking/portaging $\bigcirc$ swimming

4. What was the flow of the river when your injury occurred?
$\bigcirc$ low
medium
high
N/A (Chronic)

5. What was the difficulty of the rapid where your injury occurred?
01
O III
○
O II
O IV
$\bigcirc \mathrm{VI}$
N/A (chronic)

6. What class boater were you at the time of injury?
$\bigcirc \mathrm{I}$
○ III
$\mathrm{O}$
$\bigcirc$ II
O IV
$\bigcirc \mathrm{VI}$

7. In what year did this injury take place?

\begin{tabular}{|c|c|}
\hline 1997 & $\bigcirc 1995$ \\
\hline 1996 & $\bigcirc 1994$ \\
\hline
\end{tabular}

Figure 1 continued.

more skilled kayakers. This was probably because more of their injuries occurred while they were swimming $(21 \%$ novice compared with $11 \%$ intermediate and $7 \%$ expert). On the other hand, expert kayakers suffered more overuse injuries.

Discussion

Owing to the retrospective nature of this study, a major limitation is that kayakers who dropped out of the sport because of injury or other factors are not included and therefore we cannot calculate true injury rates. However, this study does provide important new information on kayaking injuries. As detailed by Finch, ${ }^{15}$ the definition and grading of sports injuries can be performed from various perspectives. As she reviews, medically insignificant injuries may be of major importance to an athlete. This study focused on three of the six factors listed by Finch as important in injury surveillance: the nature of the injury, the sports time lost, and the long term disability. One of the most notable findings of our study is that, although injuries were reported by slightly more than half of the respondents, very few of the injuries resulted in long term poor outcomes as reported by the respondents. Only $4 \%$ reported not having a good or complete recovery, even though almost a third of the kayakers reported missing more than one month of kayaking because of injury. In subgroup analysis, we 
8. Please indicate the parts of your body that were injured. (You may select more than one option.)

$\begin{array}{ll}\square \text { None (eg hypothermia only) } & \\ \square \text { Head } & \square \text { None } \\ \square \text { Upper back } & \square \text { Lower back } \\ \square \text { Left rib } & \square \text { Right rib } \\ \square \text { Pelvis } & \square \text { Right hip } \\ \square \text { Left hip } & \square \text { Right leg } \\ \square \text { Left leg } & \square \text { Right ankle } \\ \square \text { Left ankle } & \square \text { Right foot } \\ \square \text { Left foot } & \square \text { Right shoulder } \\ \square \text { Left shoulder } & \square \text { Right arm } \\ \square \text { Left arm } & \square \text { Right wrist } \\ \square \text { Left wrist } & \square \text { Right hand } \\ \square \text { Left hand } & \end{array}$

9. Indicate the types of injury for this event. (You may select more than one option.)

$\begin{array}{ll}\square \text { dislocation } & \square \text { abrasion/laceration } \\ \square \text { fracture } & \square \text { hypothermia } \\ \square \text { sprain } & \square \text { near drowning } \\ \square \text { tendinitis } & \square \text { contusion (bruise) }\end{array}$

10. Did you seek medical attention for this injury?
$\bigcirc$ yes
no

11. How much time did you take off from paddling as a result of this injury?
none
less than one week
less than one month
greater than one month

12. What was the outcome of this injury?

Complete recovery with no related problems

Good recovery but some problems (please describe below)

Poor outcome (please describe below)

\section{Comments:}

Figure 1 continued.

found that kayakers who were injured in the year preceding the survey had over twice the rate of poor outcome as those injured in other years $(8.7 \%$ v $3.6 \%)$. Further follow up would be needed to determine whether injury patterns have changed recently or if this merely reflects improved self reported outcome over time.

Overuse injuries, accounting for about one quarter of injuries, had the worst outcome in terms of time off from kayaking, followed by traumatic stress, with the best outcomes associated with impact injuries. Although this may at first seem counterintuitive, the less dramatic overuse injuries are typically chronic and require prolonged abstinence of the inciting mechanism for recovery - that is, not kayaking for an extended period of time - which was our measurement of "severity". Impact injuries, on the other hand, may seem more dramatic

Table 2 Basic details of the whitewater kayakers who responded to the survey and injury events May 1997 to September 1997

\begin{tabular}{lrl}
\hline No of men & 326 & $(83 \%)$ \\
No of women & 66 & $(17 \%)$ \\
Mean (SD) age (range) & 34 & $(9.3)(13-70)$ \\
Mean (SD) years boating (range) & $7.7(7.6)(0-55)$ \\
Injury events & \\
$\quad$ None & 173 \\
One & 177 \\
Two & 28 \\
Three & 9 \\
$>$ Three & 5 \\
\hline
\end{tabular}




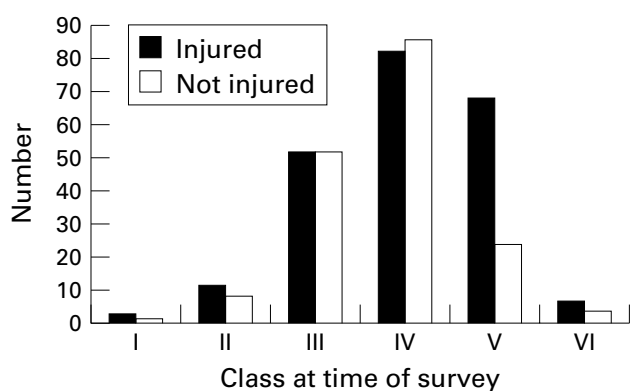

Figure 2 Injuries by class of kayaker.

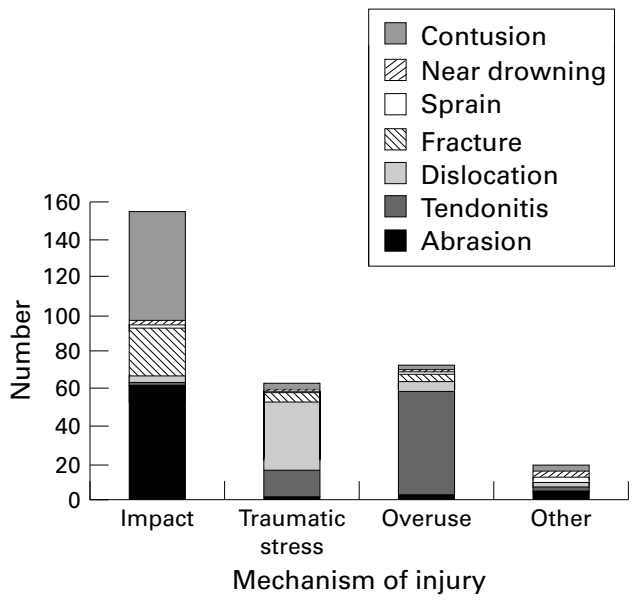

Figure 3 Injury type by mechanism.

initially, but were often abrasions, contusions, and lacerations, all of which heal rather quickly.

Another important finding of this study is that it appears that most injuries were not due to kayakers using rivers above their skill level. Only $10 \%$ of the injuries occurred to class II kayakers, yet $19 \%$ of the injuries were in class II rapids. Conversely, $25 \%$ of the respondents considered themselves expert (class V or VI) kayakers at the time of injury, but only $16 \%$ of injuries occurred in class V or VI rapids. The implications of this finding are that efforts to ensure that kayakers stay within their skill level will not be effective in lowering injury rates. An important caveat, however, is that it is possible that some kayakers suffered significant injuries in whitewater above their ability and died or gave up the sport. As mentioned above, these injuries would not be accounted for in our study.

It is of concern that $16 \%$ of the injuries were to the head/face and another $6 \%$ were to the neck. This study did not separate head from facial injuries, a finding that would be significant if a substantial number of these injuries were head and not facial injuries. Fortunately, helmets are universally accepted among kayakers. Although significant head injuries appear to be uncommon in kayaking (none were reported in studies by Burrell and Burrell, ${ }^{10}$ Kizer, ${ }^{9}$ or Wallace ${ }^{16}$ ), when they do occur in kayaking, the outcome can be catastrophic because they can lead to drowning. ${ }^{11-14}$ Such injuries would obviously be missed by this study. Facial injuries, however, are not rare; Whisman and Hollenhorst ${ }^{17}$ reported that 33\% of rafting injuries were to the face, and some kayakers have taken to wearing helmets with built in or add on face masks.

The incidence of injuries to the upper extremity $(62 \%)$ may be explained by the fact that it is very exposed and provides most of the "muscle" for kayaking, making it susceptible to overuse, traumatic stress (transmitted force), and impact injuries. Previous studies have also noted the preponderance of such injuries, ${ }^{491018}$ and paddling instructors focus on technique as being critical for preventing or at least minimising upper extremity injuries such as tendinitis and shoulder dislocations.

Our results are consistent with those of two other studies looking at kayaking injuries. In 1987, Kizer ${ }^{4}$ published a retrospective study of kayaking injuries, which found that, although a significant number of kayakers reported injuries, the vast majority were self limiting. However, as in the present study, his study was limited by its retrospective nature and could not account for kayakers who gave up the sport.

Wallace ${ }^{16}$ examined whitewater injuries from another perspective. He restricted the study to "close calls and serious injuries", reporting on 225 separate incidents. The basic characteristics of the subjects in this study are similar to those in the study of $\mathrm{Kizer}^{4}$ and our study: $79 \%$ of respondents were male (compared with $83 \%$ in our study) and most injured kayakers were 20-39 years old. The anatomical distribution of injuries was similar, with $45 \%$ of injuries reported being shoulder dislocations. His study did report a higher incidence of "neardrownings" $(11 \%)$ and fatalities $(8 \%)$, reflecting the focus of that study on serious injuries and the present study's retrospective nature.

As mentioned above, an obvious limitation is the nature of retrospective surveys. Although this technique has been used and validated in other studies of sports injury, ${ }^{19-22}$ kayakers who dropped out of the sport because of injury, or death, could not be included. Therefore, by the very nature of the study, true injury rates cannot be calculated. Also, the collection of data via the internet imposes a self selection bias of participants. A comparison of the data collected face to face with those collected using the internet shows a significantly higher injury incidence in the former group $(72 \% v 59 \%$, $\mathrm{p}<0.05)$. This difference may be due to the sampling technique used for the face to face interviews, which relied heavily on responses from whitewater club members and kayak slalom racers. As noted elsewhere, ${ }^{23-25}$ the broad reach and anonymous nature of web based interviews may allow medical researchers to gather data more quickly from subjects who would otherwise be difficult to reach. Web based surveys have been used for injury assessment in rock climbing as well as for more traditional health and mental health assessments. ${ }^{26-28}$ Web based surveys have been compared with face to face interviews, with minimal differences in results noted..$^{23-28}$

A final limitation of the study is that it was not designed to assess factors leading to specific injury events. Although descriptive data on kayaking injuries may provide a 
starting point for future work on injury prevention, studies addressing specific causes for injuries are needed. Work along these lines has been carried out by Charles Walbridge, who has compiled and discussed fatal river injuries in the American Canoe Association reports. ${ }^{11-14}$

CONCLUSION

Although about $60 \%$ of kayakers reported an injury within the past five years, very few of these injuries were felt to result in poor outcome $(4 \%)$. The number of days a kayaker spent on the river was clearly related to the likelihood of injury, which usually occurred while the kayaker was still in the boat. Kayakers also appeared to be injured more often on rapids at or below their skill level than on rapids above their skill level. Improving paddling technique may be one approach to limiting injuries; this would be expected to have the greatest impact on chronic injuries such as tendinitis and perhaps also traumatic impact injuries such as shoulder dislocations, because these injuries are most often related to poor technique.

The sport of whitewater kayaking has been growing and evolving at a rapid pace over the last few years. Future studies looking at the recently popular "rodeo boating" may find different injury patterns. With the ever more common use of the internet, prospective web based studies, supplemented with mailed surveys, may be a feasible method of accurately following kayakers, and other athletes, to assess injury rates.

Special thanks go to David Deyhimy for data collection and entry, and to Inmaculada B Aban PhD for assistance with statistics.

1 Jenkins D. Statement of conservation and public policy. Springfield, VA: American Canoe Association, 1998.

2 Marwick P. Human powered outdoor recreation 1997: state of the industry report. Outdoor recreation coalition of america Speciality sports groups and industry council, 1997. http:/ www.orca.org/research/9750I

3 Cordell HK, Tealsey J, Super G, et al. Outdoor recreation in the United States: results from the natinal survey on recreation and the environment. United States Forest Service, 1997. http://www.fs.fed.us/research/rvur/recreation/publications/ Outdoor Recreation/title.htm

4 Kizer K. Medical aspects of white-water kayaking. Physician and Sportsmedicine 1987;15:128-37.

5 Baker S, Atha J. Canoeists' disorientation following cold immersion. Br F Sports Med 1981;15:111-15.

6 Reisberg B, Wurtz R, Diaz P, et al. Outbreak of leptospirosis among white-water rafters-Costa Rica, 1996. FAMA 1997;278:808.

7 Landers D, Seppi K, Blauer W. Seizures and death on a white river float trip: report of water hemlock poisoning. West f Med 1985;142:637-40.

8 Kizer W. Whitewater medicine. Emerg Med 1987:91-106.

9 Kizer W. Medical problems in whitewater sports. Clin Sports Med 1987;6:663-9.

10 Burrell C, Burrell R. Injuries in whitewater paddling. Physician and Sportsmedicine 1982;10:119-24.

11 Walbridge C. American Canoe Association river safety report 1986-1988. Newington, VA: American Canoe Association, 1986.

12 Walbridge C. American Canoe Association river safety report 1982-1985. Lorton, VA: American Canoe Association, 1986.

13 Walbridge C. American Aanoe Association river safety report 1989-1991. Springfield, VA: American Canoe Association, 1991.

14 Walbridge C. American Canoe Association river safety report 1992-1995. Birmingham, AL: Menasha Ridge Press, 1996.

15 Finch C. An overview of some definitional issues for sports medicine injury surveillance. Sports Med 1997;24:157-63.

16 Wallace D. Dancing with risk: the results of the 1991 AWA close calls and serious injury study. American Whitewater, 1992.

17 Whisman S, Hollenhorst S. Injuries in commercial whitewater rafting. Clin F Sports Med 1998.

18 Shephard RJ. Science and medicine of canoeing and kayaking. Sports Med 1987;4:19-33.

19 Ueland O, Kopjar B. Occurrence and trends in ski injuries in Norway. Br f Sports Med 1998;32:299-303.

20 Williams J, Wright $\mathrm{P}$, Currie CE, et al. Sports related injuries in Scottish adolescents aged 11-15. Br F Sports Med 1998; 32:291-6.

21 Walter SD, Sutton JR, McIntosh JM, et al. The aetiology of sports injuries: a review of methodologies. Sports Med $1985 ; 2: 47-58$.

22 Meeuwisse W, Love E. Athletic injury reporting: development of universal systems. Sports Med 1997;24:184-204.

23 Kiesler S, Sproull L. Response effects in the electronic survey. Public Opinion Quarterly, 1986;50:402-13.

24 McKinney W, Barnas G, Golub R. The medical applications of the internet: informational resources for research, education and patient care. $\mathcal{F}$ Gen Intern Med 1994;9:62734.

25 Houston J, Fiore D. Online medical surveys: using the internet as a research tool. MD Computing 1998;15:116-20.

26 Paige T, Fiore D, Houston J. Injury in traditional and sport rock climbing. Fournal of Wilderness and Environmental Medicine 1998;9:2-7.

27 Goritz A, Schumacher J. The WWW as a research medium: an illustrative survey on paranormal belief. Percept Mot Skills 2000;90:195-206.

28 Jones R, Pitt N. Health surveys in the workplace: comparison of postal, email and World Wide Web methods. Occup Med (Lond) 1999;49:556-8.

Take home message

About half of the whitewater kayakers surveyed reported having been injured in the previous five years. Although half of these injured kayakers sought medical care and one third missed a month or more of kayaking because of their injury, $96 \%$ reported a good or complete recovery 